attraction at the same distance more than a thousand million billion billion times, the atoms being regarded as spheres oppositely electrified each to about the potential of a volt, the gravitative attraction between two worlds the size and density of our earth exceeds their electrical attraction when likewise oppositely charged each to a volt in just about the same ratio. The ratio of the forces depends, in fact, on the fourth power of the linear dimensions of the bodies concerned-other things being fixed. For a couple of small bullets the two forces would be approximately equal.

Again, if every atom be regarded as separately charged, and able to combine with each other, we get the maximum possible energy of combustion, which may but down as at the most 20,000 therms per gramme. The heat of formation of our moon by combustion is on this estimate very comparable to that developed by the falling together of its materials from infinity under gravitation. But whereas the energy of combustion is simply proportional to the masses concerned, the energy of gravitation is proportional to the product, i.e. to the second power of the masses; and so we find that when a body is as big as the sun the gravitative energy of its mere earthquake subsidence as it shrinks is enormously greater than that which could be afforded by the combustion of an equal mass. So also it is shown to ba greater than could be caused by any reasonably permissible hail of meteorites from infinity : meaning by "reasonably permissible," such a hail as would not introduce planetary perturbations of a conspicuously mon-existent amount.

Returning now to the beginning of the volume, we find an altogether admirable, but rather stiff discourse on capillarity. How it can help being stiff when it enters into problems usually treated by the higher mathematics, and hitherto reserved for specialists, I do not know. It is a serious mathematical essay done into ordinary language. The diagrams of the precise shape of liquid surfaces are beautiful, and such as are nowhere else to be found. To a reader who will concentrate his thought upon this discourse, it will gradually become luminously clear, but perhaps the conscientious person who always reads books from cover to cover, may run the risk of being choked off by the accident of its coming first.

Appended to it are three notes, one on the "tears of strong wine," as explained by Prof. James Thomson ; one on the author's remarkable and beautiful discovery of the reasons why mist globules cannot form without a nucleus, why big rain-drops form at the expense of little ones, and why put-away clothes get damp; and lastly, a note on the sufficiency of Newtonian gravitation to explain cohesion. This latter is a highly ingenious piece of special pleading. It is so easy to prove that gravitation will not explain cohesion, on any of the commonly current mental ideas of what atoms are like ; but here, by assuming a sufficiently violent concentration of substance in certain regions, and sufficient absence of all substance from other regions of an atom, it is shown that cohesion may be explained by gravitation. At least, it can be seen that different atoms can cling to each other, but it is not so clear how the various parts of the atoms themselves hang together. No-how, it seems to me, unless they are exaggeratedly fibrous structures, and unless the ends of the fibres of one atom cling on to the next, and thus build up a body like a cobweb. Nothing but cobweb can cohere by gravitation, so it seems to me (perhaps wrongly, of course); and although one has gradually learnt that no hypothesis concerning reality is a priori absurd or unlikely, yet this does not feel, nor indeed is it intended, as anything final or satisfactory.

Then comes a long lecture on electrical units of measurement, wherein the foundations of the conventional "absolute" systems of electrical measurement are explained and illustrated by showing how by means of electrical observations the fundamental standards of length, mass, and time might, if lost, be conceivably recovered. The subject is rather technical, and scarcely of sufficient general interest to repay the unelectrical reader, though there are here, as everywhere, numerous suggestive remarks. One might, perhaps, suggest that the distinction between the conventional and the essential is not always sufficiently borne in mind and enforced.

The lecture on the size of atoms is intensely interesting to everybody. Physicists know by how many different lines of argument a limit of smaliness for the space occupied by an atom can be fixed, or an actual estimate of the number of molecules in a given lump of matter can be made. A number of these methods suggested by the author are here stated, and, with many illustrations, explained. But, besides this, there are instructive mechanical models or images illustrating Prof. Stokes's theory of phosphorescence, Cauchy's theory of dispersion, and the polarization of light by small particles.

The remaining subjects dealt with in this volumeelasticity regarded as a mode of motion, and a kinetic theory of matter--are closely related to each other, are wholly the author's own, and are among the most brilliant speculations of the century. But a small inkling of the great field thus opened up is given here-enough, however to afford to the reader some glimpse of the possibilities of development lying in this direction.

Such are the contents of the volume before us, and a more comprehensive collection of scientific addresses has seldom been published. They do not, of course, really represent Sir William Thomson at his best: neither they nor any other intelligible production of his is able to convey to the general reader an adequate notion of the magnitude of his solid work, or of the grounds for the veneration with which his contemporaries regard him.

Such as they are, however, every physicist will be glad to read these papers again in this handy form, and every intelligent and educated man who feels an interest in the strong thought of physical science during this eventful century will do well to make a serious effort to grasp at least the main outlines of the profound studies shadowed forth in this small volume. Oliver J. LODGE.

\section{THE MATHEMATICAL THEORY OF POLITICAL ECONOMY.}

Éléments d'Économie Politique Pure. Par Léon Walras. (Lausanne: F. Rouge, I889.)

THE appearance of a new and enlarged edition affords us a wished-for opportunity of calling attention to this original work. Its author is one of the favoured few 
to whom bclongs the honour of having made a discovery in political economy. The title of Ricardo to the theory of rent is not better than the title of Prof. Walras to a theory more comprehensive than that of rent. It is a claim founded on originality rather than priority. Prof. Walras is the last of a small band of original thinkers who, in the latter half of this century, have independently excogitated the cardinal article in the doctrine of value. They have contemplated in different aspects the same fundamental conception: that value in exchange is neither simply identical with, nor wholly different from, value in use, but corresponds to the utility of the last, the least useful, portion of the commodities exchanged. "Nutzlichkeit des letzten Mengentheilchens," "Degree of Final Utility," "Grenznutzen," and "Rareté"--in different tongues and various terminology they proclaim the one essential truth which will be for ever associated with the names of Gossen, Jevons, Menger, and Walras.

This chronological, and, as it happens, alphabetical, arrangement is not identical with the order of merit. In that order we should place nearest together the names which are first and last in the series above written. Gossen appears to have been a mere specialist with few valuable ideas beyond the one which has made him immortal. Prof. Walras's light is more diffused. Yet it is true that we find in him rather multum than multa; that his principal achievement is the copious exposition of the one fundamental theorem to which we have referred. His next most important contribution to the stock of economic ideas relates to the function of the entrepreneur. Prof. Walras is one of the first who correctly conceived the entrepreneur as buying agencies of production (use of land, labour, and capital), and selling finished products in four markets, which thus become interdependent. His criticisms of the English school on this head are often valuable. Of the entrepreneur's funds, not pre-determined in the sense which some have imagined to any particular form of outlay, he well says :-

"Il serait aussi impossible de distinguer ce fonds de roulement du travail du fonds de roulement de la rente foncière, ou du fonds de roulement du profit, que de distinguer dans un bassin à trois robinets l'eau destinće à s'écouler par un robinet de celle destinée a s'écouler par les deux autres."

But surely he goes too far in the way of abstraction when he insists that the ideal entropreneur should be regarcled as "making neither gain nor loss":-

"Pour ce qui est de la part du profit constituant le bénéfice de l'entrepreneur l'école anglaise ne sort pas qu'elle est alcatoire, qu'elle dépend des circonstances exceptionelles, et non pas normales, et que, théoriquement, elle doit ĉtre négligée."

Perhaps his views on this and other points would have been more exact if he had considered the part which the "disutility" of labour-to use Jevons's phrase-plays as a factor of economic equilibrium, instead of confining his attention to "final utility." Another theory to which we ought to call attention is contained in the lesson on capitalization, which is added in the new edition. If the price of capital is determined by competition, it follows from the general theory of supply and demand that the maxi- mum utility of all the parties concerned is realized in the same sense as in other markets. What is more than this in the newly-added theory has baffled us.

In the case just-noticed and others, the argument is probably rendered obscure, or at least unattractive, by the use of symbols in excess of the modest requirements of elementary mathematical reasoning. The exuberance of algebraic foliage, rather than the fruit of economic truth, is the outcome of science thus cultivated. It is remarkable that the neatness which characterizes Prof. Walras's literary style, should not be reflected in his mathematical compositions. As an algebraist he has not attended to the maxim, Il ne faut pas épuiser les choses. We shall justify our criticism by referring to the chapters or "lessons," in which it is attempted to analyze what is called the "tâtonnement" of the market. The writer gives us three courses of this analysis. He diffuses over some thirty-five pages an idea which might have been adequately presented in a few paragraphs. For it is, after all, not a very good idea. What the author professes to demonstrate is the course which the higgling of the market takes-the path, as it were, by which the economic system works down to equilibrium. Now, as Jevons points out, the equations of exchange are of a statical, not a dynamical, character. They define a position of equilibrium, but they afford no information as to the path by which that point is reached. Prof. Walras's laboured lessons indicate $a$ way, not the way, of descent to equilibrium. This is not the only topic with respect to which the laboriousness of the investigation is out of proportion to its importance.

Agreeing, therefore, in the main with Prof. Walras in his plea for the use of mathematical reasoning in economics, we fear that he may have prejudiced the cause by his advocacy. The excessive elaboration of his reasoning, compared with the simplicity of his conclusions, is calculated to excite suspicion. Moreover, he traduces the mathematical method when he applies it in such a manner as to justify the popular prejudice against abstract reasoning. $\mathrm{He}$ is surely ultra crepidam, he goes beyond the little hard matter with which the craft of the mathematician is concerned, when he offers opinions on the living organism of the industrial body, and the complexion of practical problems. His scheme of dosing the circulation by a nicely calculated injection of supplementary currency reminds us of the tailors in Swift's Laputa, who went through laborious mathematical computations in order to determine the measurements of a suit of clothes, which after all fitted very ill. When Prof. Walras offers us "the solution of the Anglo-Indian monetary problem," we think of Fluellen in the heat of the battle discoursing about the "discipline of the wars." There is a discipline adapted to the schools, and which it is profitable to have studied, but which has no direct bearing upon action.

A minor ground of complaint is formed by the extreme severity of our author's criticism, especially those which relate to the English school. We cannot think that Mill's oversights deserve the "horribili flogello" which is administered. To dismiss in a few lines "comme nul et non avenu" so much of that philosopher's reasoning appears to us rather slashing. But we are sensible that in condemning the unceremonious treatment of great men, we 
are laying down a law which applies to our own criticism of Prof. Walras. We shall therefore forbear to reduce our initial encomium by invidious reservations. When all that could be made are summed and subtracted, there would still remain to Prof. Walras the undoubted glory of an original discovery. He may say of that, as Napoleon of his victories, "Il $y$ a lì du solide que la dent de l'envie ne peut ronger." F. Y. E.

\section{MUSICAL INSTRUMENTS AND THEIR} HOMES.

Musical Instruments and their Homes. By Mary E. Brown and W. Adams Brown. (New York: Dodd, Mead, and Co., I 888.)

THIS work should prove very useful to all who are interested in music and musical instruments. Primarily it professes to be a catalogue of the collection of musical instruments made by Mrs. J. Crosby Brown, of New York; but its value has been greatly augmented by a series of essays on the music and musical instruments of Oriental and savage races. The "catalogue" portion is well illustrated with clever pen-and-ink sketches, which give, for the most part, an excellent idea of the instruments, though they do not exhibit a great amount of detail. A brief description with dimensions, and, where possible, the native name, accompanies each sketch. The catalogue is divided into geographical sections, and at the end of each is added an essay treating of the music of the country from an historical and theoretical point of view, with a general account of the native instruments. Though these essays contain little that is new or original, they nevertheless form extremely useful compilations from a large amount of scattered literature ; the references are full, and the list of authorities is a very representative one.

The sections devoted to China and India are of special interest, as dealing with regions which were the birthplaces of so many of the instruments in use amongst ourselves, changed though these be from their original forms. There seems little doubt, for example, that we owe the harmonium to China, and that instruments played upon with a bow had their original home in India, whither, too, we must refer the original use of "sympathetic strings."

Musical instruments, like all other products of man's handiwork, are subject to the laws of evolution, and each arrived at its present state by gradual stages of improvement. If the genealogies could be all followed back to the earliest stages, all instruments could be referred to such simple original forms as, for example, hollow or solid $\log s$, reeds, or hunters' bows. With the rapid disappearance of the more primitive native instruments, the difficulty of tracing the history of music backwards by means of primitive "survivals" increases year by year. Every effort should be made to collect and place on record these simple forms, as from these we greatly derive our ideas of the "dawn" of music. The magnificent work by Hipkins and Gibb furnishes us with beautiful illustrations of becautiful instruments, but does not deal with the humbler kinds. The illustrations in the present work, therefore, are especially valuable, as the primitive instruments receive equal attention with the more ela- borate. A very common error has crept into the pages of this otherwise excellent work-in the terminology. Nothing is more distinct than instruments of the "oboe" type and those of the "clarionet" type are from each other. These, though somewhat similar in general aspect, belong to different classes-the "double-reed" and the "single-reed" classes respectively; and any relationship must date back to the time when they each probably took their origin from a section of corn-stalk, the one form being sounded through the pinched end of the stalk, and the other through a slit cut in the end, and forming a vibrating or beating tongue. We find, however, in several passages a confusion of these terms. 'Thus, the Corean, Greek, and Spanish "clarionets," so called, are evidently "oboes," with double reeds for mouth-pieces. Similarly, the "pandeiro" of Madeira, not having a tense membrane, cannot be a "tambourine," however much it looks like one. The "mogugyo," or "wooden fish," of Corea and China, is called a "drum" in one passage (p. 80). But a "drum," too, must have a tense membrane, and an instrument ceases to be one if lacking this addition. The "mogugyo" is really far more closely allied to the "bell" series, though there is no general term which expresses this class of wooden instrument. Such mistakes are, doubtless, mere slips, but they are apt to be misleading.

In the description of savage music it is stated (p. 240) that the Mincopies have no musical instruments. This is not quite true, as they have one, though a simple one, and consisting merely of a hard-wood board, of special shape, which is used for sounding a rhythmical time for dancing. It is used only as a musical instrument, and so illustrates a step in advance of the Australian, who taps with a stick upon his "casting-board" for the same purpose, without employing a separate instrument.

It is to be hoped that other collectors will follow the excellent example of the authors of this work, and publish illustrated catalogues of their collections. We can hardly expect many such beautifully produced "catalogues," but the scientific spirit and easy style of this book might well be a model for others.

\section{OUR BOOK SHELF.}

Heat. By H. G. Madan, M.A., F.C.S. (London: Rivingtons, I889.)

THIs is an elementary treatise of exceptional merit, combining thoroughly practical work with sound theoretical conclusions. The course of instruction which it comprises has been found suitable by the author, in his capacity as instructor at Eton College, for boys who already have some acquaintance with physiography and elementary dynamics. Mathematical expressions are accordingly used as little as possible, and, when used at all, they are fully explained in ordinary language.

A very large number of experiments-many of them new - are described, and we have the author's assurance that they are all capable of successful performance with moderate skill and care. It is rightly observed that experiments which do not always succeed, even with the greatest care, are altogether unsuitable for young students, as they invariably tend to make them lose confidence in the science.

Particular attention is given throlighout to the application of the general laws of heat to the arts and manu- 